\title{
High-precision measurement of mercury isotope ratios of atmospheric deposition over the past 150 years recorded in a peat core taken from Hongyuan, Sichuan Province, China
}

\author{
SHI WenFang ${ }^{1,2}$, FENG XinBin $^{1 *}$, ZHANG Gan $^{3}$, MING LiLi $^{2,3}$, YIN RunSheng ${ }^{1,2}$, \\ ZHAO ZhiQi ${ }^{1} \&$ WANG Jing ${ }^{1}$ \\ ${ }^{1}$ The State Key Laboratory of Environmental Geochemistry, Institute of Geochemistry, Chinese Academy of Sciences, Guiyang 550002, China; \\ ${ }^{2}$ Graduate University of Chinese Academy of Sciences, Beijing 100049, China; \\ ${ }^{3}$ The State Key Laboratory of Organic Geochemistry, Guangzhou Institute of Geochemistry, Chinese Academy of Sciences, Guangzhou 510640, \\ China
}

Received August 19, 2010; accepted December 9, 2010

\begin{abstract}
High-precision ${ }^{210} \mathrm{~Pb}$ dating technology was applied to a peat core with a time span of about 150 years that was taken from Hongyuan, Sichuan Province, China. The concentrations of total mercury $(\mathrm{Hg})$ and stable isotope compositions of mercury in the peat core were measured using a LUMEX 915 instrument and multi-collector inductively coupled plasma mass spectrometer, respectively. Total mercury $(\mathrm{Hg})$ concentrations in the peat core had a clearly increasing trend from the bottom to top of the core while $\delta^{202} \mathrm{Hg}$ values (relative to NIST 3133) of peat had a decreasing trend. The total mercury ( $\mathrm{Hg}$ ) concentration varied from 16.7 to $101.3 \mathrm{ng} / \mathrm{g}$ and the $\delta^{202} \mathrm{Hg}$ values ranged from $-0.44 \%$ o $\pm 0.14 \%$ o to $-1.45 \%$ o $\pm 0.22 \%$. We clearly show that the study area experienced mercury pollution after the industrial revolution, and the mercury emitted from natural sources and anthropogenic sources had different $\mathrm{Hg}$ isotope signatures.
\end{abstract}

peat, ombrotrophic, mercury, isotope, industrialization

Citation: $\quad$ Shi W F, Feng X B, Zhang G, et al. High-precision measurement of mercury isotope ratios of atmospheric deposition over the past 150 years recorded in a peat core taken from Hongyuan, Sichuan Province, China. Chinese Sci Bull, 2011, 56: 877-882, doi: 10.1007/s11434-011-4396-0

The nutrients of ombrotrophic peat are mainly derived from precipitation [1-3], and the contribution from surface streams is trivial [4]. Because mercury can be transported in the atmosphere over a long range, it can reach peat through multiple pathways such as wet deposition (rain and snow), dry deposition, and litterfall input. Therefore, the amount of mercury in peat can reflect the amount of mercury in the atmosphere, and the record of the mercury distribution in peat can be used to reconstruct the history of mercury pollution in the atmosphere [5-8]. Since Martinez-Cortizas et al. [3] investigated the mercury $(\mathrm{Hg})$ distribution in a peat core in Spain, many researchers have focused on the concentrations of total $\mathrm{Hg}$ and methylmercury in peat cores, the flux

*Corresponding author (email: fengxinbin@ vip.skleg.cn) of mercury ( $\mathrm{Hg}$ ) deposition, the correlation between mercury and other heavy metals in peat cores, the effects of different analytical protocols of dating cores on the calculation of $\mathrm{Hg}$ deposition fluxes, and the response of mercury concentrations in cores to historical climate change [7,9-16].

Analytical advancements, especially the development of multi-collector inductively coupled plasma mass spectrometry (MC-ICP-MS), have allowed for accurate measurement of stable isotopes of many heavier elements such as $\mathrm{Cu}, \mathrm{Fe}, \mathrm{Zn}, \mathrm{Cr}, \mathrm{Mo}$, Se and $\mathrm{Hg}$. $\mathrm{Hg}$ has seven stable isotopes (with atomic masses of 196, 198, 199, 200, 201, 202 and $204 \mathrm{amu}$ ) with abundances of $0.15 \%, 10.02 \%, 16.84 \%$, $23.13 \%, 13.22 \%, 29.80 \%$ and $6.85 \%$, respectively. Previous studies showed a wide range of mass-dependent fractionation of mercury isotopes in various environmental matrices 
such as meteorites [17,18], volcanic hydrothermal systems [19], Hg ores [20], coals [21], and soils [22]. On the other hand, mass-independent fractionation (MIF) of mercury isotopes was observed in sediments [23], plants [24], and aquatic systems $[25,26]$. These studies have demonstrated that $\mathrm{Hg}$ isotope ratios can be widely used to fingerprint the sources of $\mathrm{Hg}$ pollution in the environment and to monitor the biogeochemical processes of $\mathrm{Hg}$ in natural systems.

Despite an increasing interest in $\mathrm{Hg}$ isotopes, studies focusing on $\mathrm{Hg}$ isotope composition of atmospheric mercury $(\mathrm{Hg})$ have been limited [27]. Because of the low mercury concentrations in the atmosphere (at the nanograms per cubic meter level), it is difficult to achieve the requirements of mercury isotope measurements at the nanograms per liter level [28,29]; therefore, direct measurements of isotope ratios of mercury $(\mathrm{Hg})$ in the atmosphere are rare in the available literature. In this paper, we report for the first time $\mathrm{Hg}$ isotope compositions and total mercury concentrations in a peat core with a 150-year-old age in Hongyuan, Sichuan Province, China, with the aim of revealing the effects of industrialization on the atmospheric pollution of mercury and the isotopic composition of mercury emitted from both natural and anthropogenic sources.

\section{Study area}

The research area is located in the Aba Qiang Autonomous Prefecture in Sichuan Province, which is adjacent to Qing- hai and Gansu provinces (Figure 1). The typical highland peat of China-Zoigê-Hongyuan peat is situated in this region. Geographically, the research area is located in the flat region of the Hongyuan highlands of the northeastern Qinghai-Tibetan Plateau and Ouqiongmake Basin on the southern side of the upstream of the Baihe River. The basin varies in elevation from 3490 to $3532 \mathrm{~m}$ a.s.l. and is higher in the south and east than in the north and west. Surface water flows from south to north and reaches the Baihe River. The surrounding mountains reach an elevation of around $3700 \mathrm{~m}$ a.s.l. The study area belongs to a typical alpine meadow steppe zone with a typical climate of the continental plateau low-temperature monsoon zone, which is characterized by a long and cold winter, no summer and short spring and fall. The annual average temperature is $1.1^{\circ} \mathrm{C}$, the average temperature in January is $-10.3^{\circ} \mathrm{C}$, and the average temperature in July is $10.9^{\circ} \mathrm{C}$. There is a great temperature difference between day and night and a long annual sunshine duration [1,2,30-33].

Because mercury $(\mathrm{Hg})$ background concentrations on the Zoigê Plateau are very low, the plateau is regarded as a typical geochemical region lacking a number of elements [34]. Therefore, the input of $\mathrm{Hg}$ through surface water to the peat bog is limited. Moreover, the peat in the study area is of a typical stream terrace type [35], and plants in the peat bog mainly obtain nutrients from precipitation. As a result, the main source of mercury $(\mathrm{Hg})$ to peat is from atmospheric deposition such as rain, snow and particle deposition.

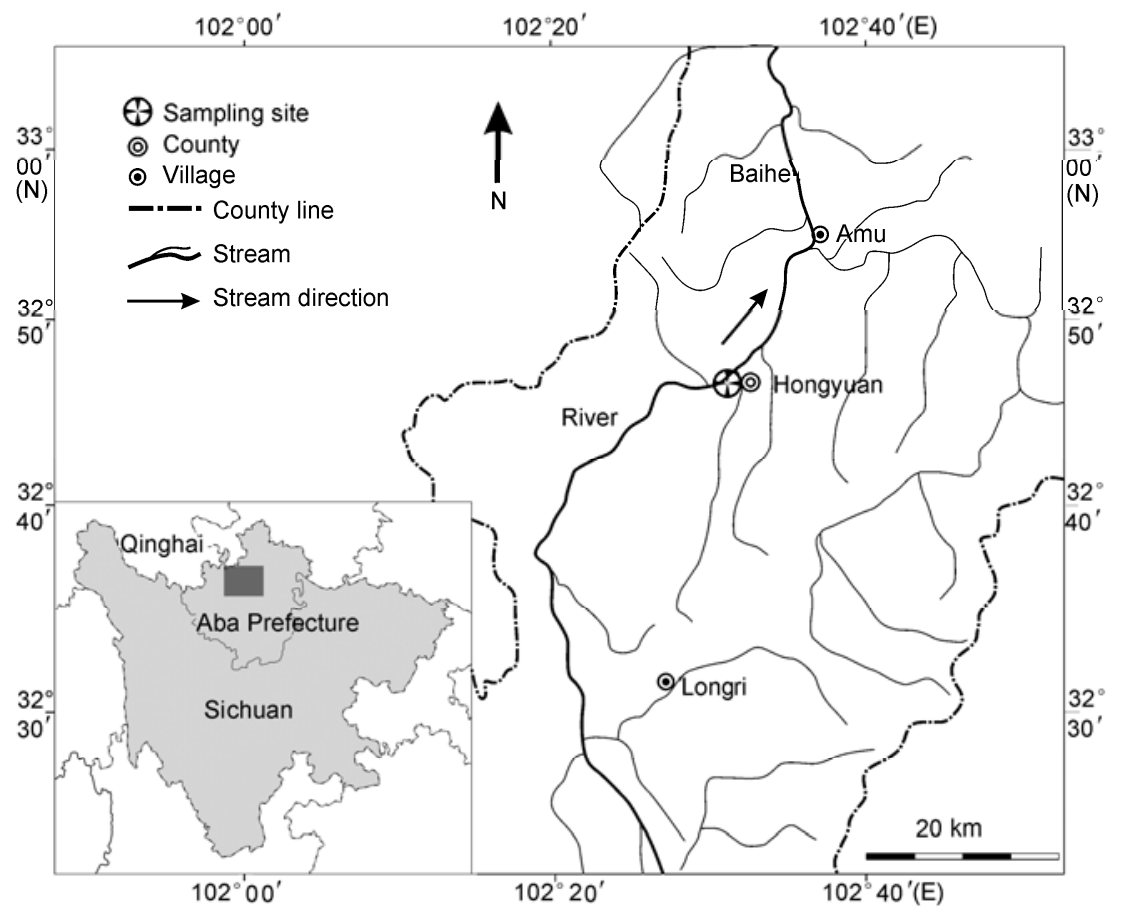

Figure 1 Location of the sampling site. 


\section{Experimental}

\subsection{Sampling methods and sample pretreatment}

A peat core with dimensions of $10 \mathrm{~cm} \times 11 \mathrm{~cm} \times 25 \mathrm{~cm}$ was collected on May 24, 2006 at the Zoigê-Hongyuan bog $\left(32^{\circ} 46.774^{\prime} \mathrm{N}, 102^{\circ} 30.964^{\prime} \mathrm{E}\right)$ using a stainless steel Wardenaar sampler. The peat core was wrapped with aluminum foil, brought back to the laboratory and stored frozen at $-18^{\circ} \mathrm{C}$ until analysis. The frozen peat core was cut into $0.5 \mathrm{~cm}$ slices with a stainless steel knife in the laboratory. Each slice was wrapped in aluminum foil and plastic bags, and the samples were vacuum-freeze-dried for $48 \mathrm{~h}$. After coarse root fragments were removed, the samples were milled, sieved through an 80-mesh stainless steel screen and stored in sealed plastic bags at room temperature until analysis.

\subsection{Dating of peat samples}

The ${ }^{210} \mathrm{~Pb}$ activity of peat samples was measured using a germanium detector gamma-ray spectrometer (EG\&G ORTEC, HPGe GWL-120-15). ${ }^{210} \mathrm{~Pb}$ was determined at $46.5 \mathrm{keV}$ and the constant initial ${ }^{210} \mathrm{~Pb}$ concentration model was used for age dating, giving an average sedimentation rate of $0.16 \mathrm{~cm} / \mathrm{a}$.

\subsection{Total Hg analysis}

Mercury concentrations were determined for the dried samples using LUMEX 915 and PYRO 915 instruments; the processes were detailed by Rodriguez et al. [36]. The accuracy $(<10 \%)$ was checked using duplicate samples and the precision was found to be better than $10 \%$. The recovery (80\%-120\%) was assessed using standard reference materials (GBW07305 and GBW07405).

\subsection{Hg isotope composition analysis}

Between 0.6 and $2 \mathrm{~g}$ of peat samples and standard reference materials were digested in $10 \mathrm{~mL}$ of a mixture of sulfuric and nitric acids $(2: 8(v / v))$ at room temperature for $24 \mathrm{~h}$, then processed in a water bath at $95^{\circ} \mathrm{C}$ for $6-8 \mathrm{~h}$ until no visible reaction was observed. A $1 \mathrm{~mL}$ quantity of $\mathrm{BrCl}$ solution was added and the volume of the sample was adjusted to $15 \mathrm{~mL}$ by adding Milli-Q water. All digested solution was filtered by passing through a $0.45 \mu \mathrm{m}$ Millipore polycarbonate membrane filter in a vacuum filtration system and stored in frozen for isotope measurement. Total mercury $(\mathrm{Hg})$ concentrations in the solution were adjusted within the range of $1.5-5 \mathrm{ng} / \mathrm{mL}$ for $\mathrm{Hg}$ isotope analysis. Total mercury $(\mathrm{Hg})$ concentrations in the samples were analyzed by cold-vapor atomic fluorescence spectrometry. The blanks and standard reference materials (GBW07305 and GBW10020) were also analyzed and the recovery ranged between $80 \%-120 \%$. For some samples, the total mass was less than $0.2 \mathrm{~g}$, which is insufficient for mercury $(\mathrm{Hg})$ isotope analysis; in such a case, we combined adjacent samples in the peat core as one sample. We thus prepared 27 peat samples for mercury $(\mathrm{Hg})$ isotope ratio analysis.

$\mathrm{Hg}$ isotope ratios were determined by MC-ICP-MS (Nu Plasma, Nu Instrument Ltd., UK) at the State Key Laboratory of Environmental Geochemistry, Institute of Geochemistry, Chinese Academy of Sciences. A cold-vapor generator (Cetac HGX-200) and Apex desolvation unit (Elemental Scientific Inc., USA) introduced $\mathrm{Hg}, \mathrm{SnCl}_{2}$ and $\mathrm{Tl}$. $\mathrm{Hg}$ in sample solutions was reduced by $\mathrm{SnCl}_{2}$ solution on-line and continuously introduced into the mass spectrometer. We corrected instrumental mass bias by simultaneous measurement of a certified thallium isotope standard (NIST SRM 997; ${ }^{205} \mathrm{Tl} /{ }^{203} \mathrm{Tl}$ ratio of 2.38714). Details of the cold vapor and Apex system, Faraday cup configuration, instrument parameters and analytical conditions used throughout this work were previously published by Yin et al. [28].

Four isotope ratios $\left({ }^{202} \mathrm{Hg} /{ }^{198} \mathrm{Hg},{ }^{201} \mathrm{Hg} /{ }^{198} \mathrm{Hg},{ }^{200} \mathrm{Hg} /{ }^{198} \mathrm{Hg}\right.$, and ${ }^{199} \mathrm{Hg} /{ }^{198} \mathrm{Hg}$ ) are reported as delta values $(\delta)$ with units of per mil (\%o) relative to the NIST SRM3133 $\mathrm{Hg}$ solution. MIF anomalies are calculated using the "capital delta" notation, $\Delta^{\mathrm{xx}} \mathrm{Hg}(\%)$, following the equations suggested by Blum and Bergquist [29]:

$$
\begin{aligned}
\delta^{\mathrm{XXX}} \mathrm{Hg}(\% o)= & 1000 \times\left[\left({ }^{\mathrm{XXX}} \mathrm{Hg} /{ }^{198} \mathrm{Hg}\right)_{\text {unknown }}\right. \\
& \left./\left({ }^{\mathrm{XXX}} \mathrm{Hg} /{ }^{198} \mathrm{Hg}\right)_{\mathrm{NIST} 3133-1}\right], \\
\Delta^{199} \mathrm{Hg}(\% o)= & \delta^{199} \mathrm{Hg}-\left(0.252 \times \delta^{202} \mathrm{Hg}\right), \\
\Delta^{200} \mathrm{Hg}(\% \circ)= & \delta^{200} \mathrm{Hg}-\left(0.502 \times \delta^{202} \mathrm{Hg}\right), \\
\Delta^{201} \mathrm{Hg}(\% \circ)= & \delta^{201} \mathrm{Hg}-\left(0.752 \times \delta^{202} \mathrm{Hg}\right),
\end{aligned}
$$

where XXX represents 202, 201, 200 and 199, respectively.

Uncertainties reported in this paper correspond to the larger value of the uncertainty of repeated measurements of the same digest in different analysis sessions. When the calculated 2SD was smaller than that of the replicate analyses of the reference material UM-Almaden, the uncertainty associated to UM-Almaden was used instead [28].

\section{Results and discussion}

\subsection{Total $\mathrm{Hg}$ in the peat core}

The distribution of the total $\mathrm{Hg}$ concentration in the peat core as shown in Figure 2 has a generally increasing trend from the deeper part of the core to the surface, ranging between 16.7 and $101.3 \mathrm{ng} / \mathrm{g}$. Three periods can be recognized from this core. During the first period from 1840 to 1900 , total mercury $(\mathrm{Hg})$ concentration was constant with an average value of $19 \mathrm{ng} / \mathrm{g}$. In the second period between 1900 and 1985 , the total $\mathrm{Hg}$ concentration almost doubled. In the 
final period commencing in 1985 , there was a strong increasing trend of the total mercury $(\mathrm{Hg})$ concentration.

This result indicates that the mercury concentration in the atmosphere was quite low and stable in the study area before 1900, because mercury emissions during early industrialization in Europe and North America had little effect on the study area and the mercury in peat probably mainly originated from natural sources. With the acceleration of industrialization in Europe and North America since 1900, especially with the increase in mercury emissions from coal combustion, the $\mathrm{Hg}$ concentration in peat increased significantly. Clearly, mercury emissions from human activities in Europe and North America increased mercury concentrations in the ambient air in the study area owing to the long-range transportation of mercury in the atmosphere with circulating air mass. The economic development in China since the 1980 s significantly increased the mercury concentration in the ambient air in the study area.

\subsection{Isotopic composition of $\mathrm{Hg}$ in the peat core}

The $\delta^{202} \mathrm{Hg}$ values of peat core ranged from $-0.44 \%$ \pm $0.14 \%$ o to $-1.45 \%$ $\pm 0.22 \%$, and the $\delta^{202} \mathrm{Hg}$ profile can be divided into the same three periods as for $\mathrm{THg}$ as shown in Figure 3. Between 1840 and 1900, the average value of $\delta^{202} \mathrm{Hg}$ in peat was $-0.57 \%$ $\pm 0.13 \%$. The average value decreased to $-0.87 \% \circ \pm 0.16 \%$ o during the period $1900-1985$ and further to $-0.99 \% \circ \pm 0.05 \%$ after 1985 .

Using the following simple binary mixing model proposed by Foucher et al. [22], the relative contribution of all $\mathrm{Hg}$ sources to the peat was calculated as

$$
\begin{gathered}
\delta^{202} \mathrm{Hg}_{\text {samp }}=X_{\text {ns }} \times \delta^{202} \mathrm{Hg}_{\mathrm{ns}}+X_{\text {as }} \times \delta^{202} \mathrm{Hg}_{\text {as }}, \\
X_{\text {ns }}+X_{\text {as }}=1,
\end{gathered}
$$

where $\delta^{202} \mathrm{Hg}_{\text {samp }}, \delta^{202} \mathrm{Hg}_{\mathrm{ns}}$ and $\delta^{202} \mathrm{Hg}_{\text {as }}$ are the isotopic compositions of the peat sample, mercury originating from

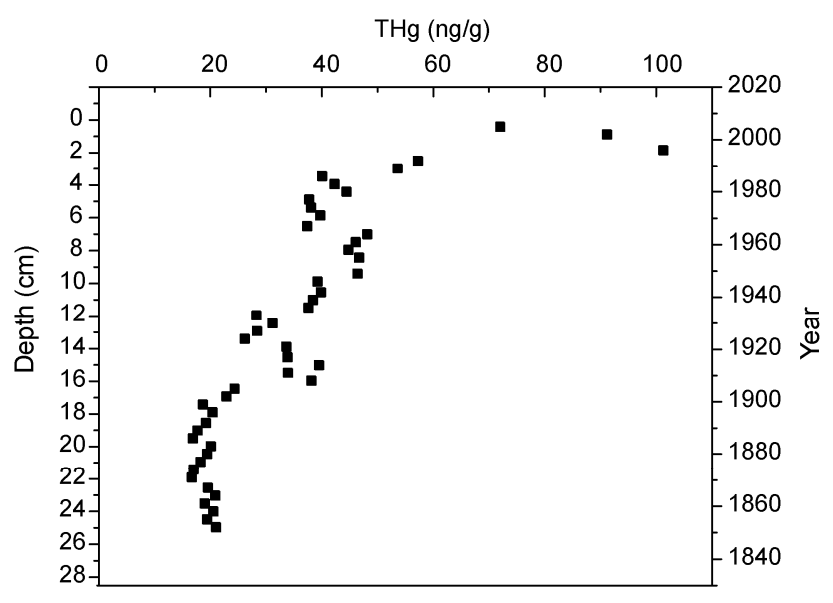

Figure 2 Mercury concentrations in the peat core.

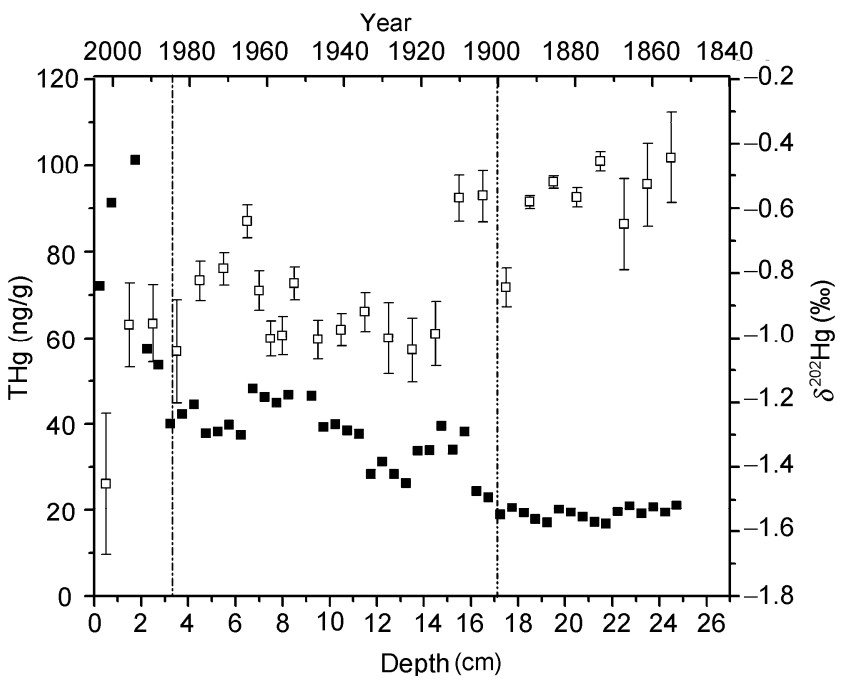

Figure 3 Variations in $\mathrm{THg}$ total $\mathrm{Hg}$ concentrations and $\delta^{202} \mathrm{Hg}$ values in the dated peat core taken from Hongyuan.

natural sources and mercury originating from anthropogenic sources, respectively; $X_{\mathrm{ns}}$ and $X_{\mathrm{as}}$ are the contribution factors of natural sources and anthropogenic sources to the peat samples. Here, we assume that all the mercury in peat originated from natural sources before 1900, whereas mercury in peat after 1900 originated from both natural and anthropogenic sources. The calculations show that mercury emitted from anthropogenic sources in Europe and North America had an average value of $\delta^{202} \mathrm{Hg}$ of $-1.16 \%$ o $0.15 \%$, and the average value of $\delta^{202} \mathrm{Hg}$ is $-1.12 \% 0 \pm 0.08 \%$ o for mercury emitted in China.

Figure 4 shows the MIF of mercury isotopes with odd atomic masses. All peat samples had positive $\Delta^{199} \mathrm{Hg}$ and $\Delta^{201} \mathrm{Hg}$ values, which indicates the mercury isotopes with odd atomic masses are enriched in peat.

MIF is generally believed to be result from the magnetic isotope effect and/or the nuclear field shift [37,38]. Previous studies have demonstrated that MIF can be induced by photochemical reduction of $\mathrm{Hg}^{2+}$ and methylmercury, and results in the depletion of odd isotopes in the gas phase. In $\Delta^{199} \mathrm{Hg}$ versus $\Delta^{201} \mathrm{Hg}$ plots for each of these photochemical reduction processes, there is a slope of 1.36 for methylmercury and 1.00 for $\mathrm{Hg}^{2+}$ photoreduction. Zheng et al. [38] indicated that the photoreduction of $\mathrm{Hg}$-DOC species can produce slopes ranging from 1.19 to 1.543 . However, as proposed by Estrade et al. [39], a liquid-vapor evaporation experiment under dynamic conditions led to negative anomalies of the isotopes with odd atomic masses in the residual liquid fractions yielding a $\Delta^{199} \mathrm{Hg} / \Delta^{201} \mathrm{Hg}$ ratio of $2.0 \pm 0.6$, which is statistically the same as that predicted for the nuclear field shift effect $\left(\Delta^{199} \mathrm{Hg} / \Delta^{201} \mathrm{Hg} \approx 2.47\right)$.

The $\Delta^{201} \mathrm{Hg}$ versus $\Delta^{199} \mathrm{Hg}$ plot of peat samples is shown in Figure 5. Samples prior to 1900 (i.e. below $16 \mathrm{~cm}$ in depth and presented as hollow triangles) had a $\Delta^{201} \mathrm{Hg} /$ 

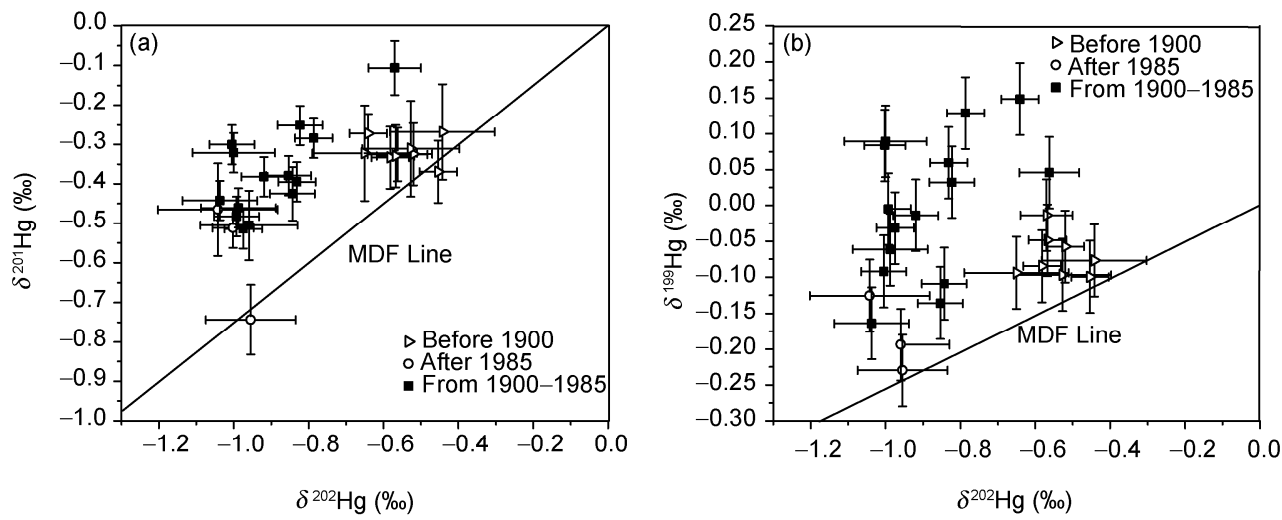

Figure $4 \mathrm{MIF}$ of ${ }^{199} \mathrm{Hg}$ and ${ }^{201} \mathrm{Hg}$ for all peat samples.

$\Delta^{199} \mathrm{Hg}$ ratio close to 1 . This indicates that MIF can be attributed to the photoreduction of $\mathrm{Hg}$ (II) and that the sources of mercury are natural. Interestingly, the samples after 1900 did not show any clear trends for $\Delta^{201} \mathrm{Hg} / \Delta^{199} \mathrm{Hg}$, which suggests that that there are different MIF mechanisms for mercury from different sources.

Many concurrent processes, such as methylation, demethylation, photo-oxidation [40] and re-emission of mercury in peat $[10,15]$ could induce fractionation of mercury isotopes, but their contributions to isotope fractionation are not fully characterized.

Although we could not determine the dominant process resulting in mercury isotope fractionation in peat after industrialization in Europe and North America, our study clearly indicates that mercury emitted from natural sources has a significantly different isotope composition than that emitted from anthropogenic sources. This difference could result from the emission processes and mechanisms of natural processes being different from those of anthropogenic sources [41]. First, most natural mercury emission processes release mercury gradually under room-temperature conditions, whereas most anthropogenic processes emit

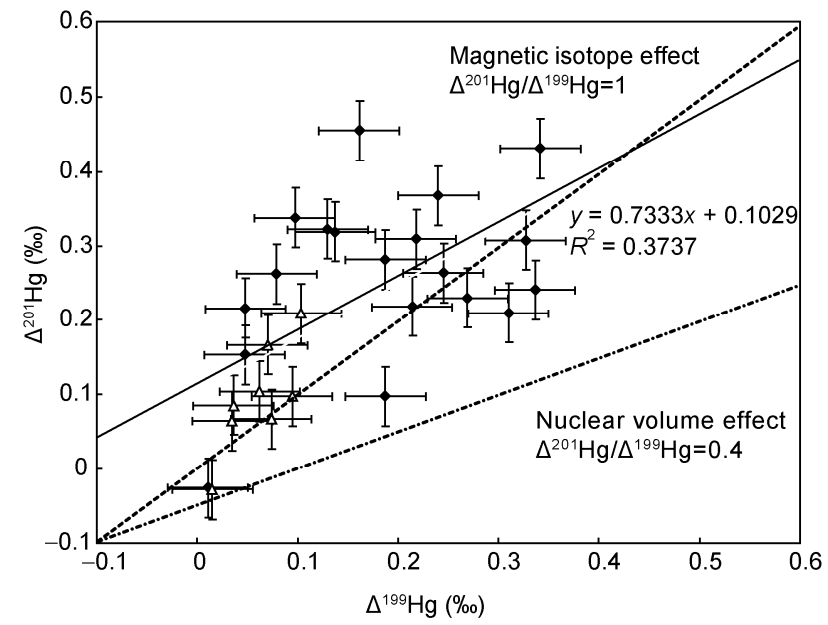

Figure $5 \quad \Delta^{199} \mathrm{Hg}$ vs. $\Delta^{201} \mathrm{Hg}$ plot for all peat samples. mercury at elevated rates under high-temperature conditions. Moreover, the emission of $\mathrm{Hg}$ in natural processes is mainly driven by the reduction of $\mathrm{Hg}^{2+}$ to $\mathrm{Hg}^{0}$ through microbiological, chemical and photochemical processes, while the emission of mercury from anthropogenic sources is mainly controlled by the thermal reduction of $\mathrm{Hg}^{2+}$ at high temperatures [41]. These differences result in the different mercury isotope compositions for different mercury emission sources.

\section{Conclusions}

In this study, we investigated total mercury concentrations and mercury isotope compositions in a peat core collected from the Hongyuan peat bog in the northeast of the Qinghai-Tibetan Plateau. We observed that total mercury concentrations in peat increased after industrialization in Europe and North America, which demonstrated that mercury emission from human activity has increased since then. We also observed that mercury isotope compositions in peat before and after industrialization in Europe and North America are significantly different. Mercury isotope compositions from anthropogenic sources are slightly lighter than those from natural sources. Moreover, MIF of isotopes with odd atomic masses showed a distinct difference between natural mercury emission sources and anthropogenic sources. This evidence confirms that mercury emitted from different sources (natural and anthropogenic sources) has different mercury $(\mathrm{Hg})$ isotope ratios and different mercury isotope fractionation mechanisms. Our study highlights the importance of studying isotopic compositions of mercury emitted from different sources.

The authors would like to thank Dr. Qiu Guangle, anonymous reviewers and editors for constructive suggestions that improved our manuscript. This work was supported by the National Natural Science Foundation of China (40825011 and 20828008).

1 Wang H, Hong Y T, Zhu Y Y, et al. Humification degrees of peat in Qinghai-Xizang Plateau and palaeoclimate change. Chinese Sci Bull, 2004, 49: 514-519 
2 Hong B, Lin Q H, Zhu Y Y, et al. Carbon isotopic composition of the Carex Mulieenisis remain of the Hongyuan peat bog in the eastern plateau and the India Ocean sumer monsoon variation in the Holocean (in Chinese). Bull Mineral Petrol Geochem, 2003, 22: 99-103

3 Martinez-Cortizas A, Pontevedra-Pombal X, Garcia-Rodeja E, et al. Mercury in a Spanish peat bog: Archive of climate change and atmospheric metal deposition. Science, 1999, 284: 939-942

4 Rey-Salgueiro L, Pontevedra-Pombal X, Alvarez-Casas M, et al. Comparative performance of extraction strategies for polycyclic aromatic hydrocarbons in peats. J Chromatogr A, 2009, 1216: 5235-5241

5 Givelet N, Roos-Barraclough F, Goodsite M E, et al. A 6000-years record of atmospheric mercury accumulation in the high Arctic from peat deposits on Bathurst Island, Nunavut, Canada. J Phys Iv, 2003, 107: 545-548

6 Roos-Barraclough F, Martinez-Cortizas A, Garcia-Rodeja E, et al. A 14500 year record of the accumulation of atmospheric mercury in peat: volcanic signals, anthropogenic influences and a correlation to bromine accumulation. Earth Planet Sci Lett, 2002, 202: 435-451

7 Biester H, Kilian R, Franzen C, et al. Elevated mercury accumulation in a peat bog of the Magellanic Moorlands, Chile (53 degrees S)_An anthropogenic signal from the Southern Hemisphere. Earth Planet Sci Lett, 2002, 201: 609-620

8 Jensen A, Jensen A. Historical deposition rates of mercury in Scandinavia estimated by dating and measurement of mercury in cores of peat bogs. Water Air Soil Poll, 1991, 56: 769-777

9 Golovatskaya E A, Lyapina E E. Distribution of total mercury in peat soil profiles in West Siberia. Contemp Probl Ecol, 2009, 2: 156-161

10 Farmer J G, Anderson P, Cloy J M, et al. Historical accumulation rates of mercury in four Scottish ombrotrophic peat bogs over the past 2000 years. Sci Total Environ, 2009, 407: 5578-5588

11 Bulgariu L, Ratoi M, Bulgariu D, et al. Adsorption potential of mercury (II) from aqueous solutions onto Romanian peat moss. J Environ Sci Heal A, 2009, 44: 700-706

12 Klaminder J, Yoo K, Rydberg J, et al. An explorative study of mercury export from a thawing palsa mire. J Geophys Res-Biogeo, 2008, 113: 1-9

13 Ettler V, Navratil T, Mihaljevic M, et al. Mercury deposition/accumulation rates in the vicinity of a lead smelter as recorded by a peat deposit. Atmos Environ, 2008, 42: 5968-5977

14 Liu R H, Wang Q C, Lu X G, et al. Distribution and speciation of mercury in the peat bog of Xiaoxing'an Mountain, northeastern China. Environ Pollut, 2003, 124: 39-46

15 Biester H, Martinez-Cortizas A, Birkenstock S, et al. Effect of peat decomposition and mass loss on historic mercury records in peat bogs from Patagonia. Environ Sci Technol, 2003, 37: 32-39

16 Roos-Barraclough F, Givelet N, Martinez-Cortizas A, et al. An analytical protocol for the determination of total mercury concentrations in solid peat samples. Sci Total Environ, 2002, 292: 129-139

17 Lauretta D S, Klaue B, Blum J D, et al. Inductively coupled plasma mass spectrometry measurements of bulk mercury abundances and isotopic ratios in Murchison (CM) and Allende (CV). Meteor Planet Sci, 2000, 35: A95-A96

18 Lauretta D S, Klaue B, Blum J D, et al. Mercury abundances and isotopic compositions in the Murchison (CM) and Allende (CV) carbonaceous chondrites. Geochim Cosmochim Acta, 2001, 65: 2807-2818

19 Sherman L S, Blum J D, Nordstrom D K, et al. Mercury isotopic composition of hydrothermal systems in the Yellowstone Plateau volcanic field and Guaymas Basin sea-floor rift. Earth Planet Sci Lett, 2009, 279: 86-96

20 Smith C N, Kesler S E, Blum J D, et al. Isotope geochemistry of mercury in source rocks, mineral deposits and spring deposits of the California Coast Ranges, USA. Earth Planet Sci Lett, 2008, 269: 399-407

21 Biswas A, Blum J D, Bergquist B A, et al. Natural mercury isotope variation in coal deposits and organic soils. Environ Sci Technol, 2008, 42: 8303-8309

22 Foucher D, Ogrinc N, Hintelmann H. Tracing mercury contamination from the Idrija mining region (Slovenia) to the gulf of Trieste using $\mathrm{Hg}$ isotope ratio measurements. Environ Sci Technol, 2009, 43: 33-39

23 Feng X B, Foucher D, Hintelmann H, et al. Tracing mercury contamination sources in sediments using mercury isotope compositions. Environ Sci Technol, 2010, 44: 3363-3368

24 Carignan J, Estrade N, Sonke J E, et al. Odd isotope deficits in atmospheric Hg measured in lichens. Environ Sci Technol, 2009, 43: 5660-5664

25 Bergquist B A, Blum J D. Mass-dependent and -independent fractionation of $\mathrm{Hg}$ isotopes by photoreduction in aquatic systems. Science, 2007, 318: 417-420

26 Bergquist B A, Blum J D. Mass-dependent and mass-independent fractionation of $\mathrm{Hg}$ isotopes in aquatic systems. Geochim Cosmochim Acta, 2007, 71: A83-A83

27 Sherman L S, Blum J D, Johnson K P, et al. Mass-independent fractionation of mercury isotopes in Arctic snow driven by sunlight. Nature Geoscience, 2010, 3: 173-177

28 Yin R S, Feng X B, Foucher D, et al. High precision determination of mercury isotope ratios using online mercury vapor generation system coupled with Multi-collector Inductively Coupled Plasma-Mass Spectrometry (in Chinese). Chin J Anal Chem, 2010, 38: 929-934

29 Blum J D, Bergquist B A. Reporting of variations in the natural isotopic composition of mercury. Anal Bioanal Chem, 2007, 388: 353-359

30 He G R. Geological features of Hongyuan peat land I and II (in Chinese). Acta Geol Sichuan, 1998, 18: 126-130

31 Sun G Y, Luo X Z, Turner E T. A study on peat deposition chronology of Holocene of Zorge Plateau in the Northeast Qinghai-Tibetan Plateau (in Chinese). Acta Sedimentol Sin, 2001, 19: 177-181

$32 \mathrm{Xu} \mathrm{H}$, Hong Y T, Ling Q H, et al. Temperature variations in the past 6000 years inferred from $\delta^{18} \mathrm{O}$ of peat cellulose from Hongyuan, China. Chinese Sci Bull, 2002, 47: 1575-1584

33 Zhou W J, Lu W F, Wu Z K, et al Peat record reflecting Holocene climatic change in the Zoige Plateau and AMS radiocarbon dating. Chinese Sci Bull, 2002, 47: 66-74

34 Tang W C. The environmental geochemical characters and studies of Ruoergai Pasture (in Chinese). Computing Techniques for Geophysical and Geochemical Exploration, 2001, 23: 353-356

35 Yu X F, Zhou W J, Lars G F, et al. Grain size characteristics of the Holocene peat sediment in Eastern Tibetan Plateau and its paleoclimatic significance (in Chinese). Acta Sedimentol Sin, 2006, 24: 864-865

36 Rodriguez L, Rincon J, Asencio I, et al. Capability of selected crop plants for shoot mercury accumulation from polluted soils: Phytoremediation perspectives. Int J Phytoremediat, 2007, 9: 1-13

37 Stetson S J, Gray J E, Wanty R B, et al. Mercury stable isotope variability in ore, mine-waste calcine, and leachates of mine-waste calcine within a historical mercury mining district. Geochim Cosmochim Acta, 2009, 73: A1274

38 Zheng W, Hintelmann H. Mercury isotope fractionation during photoreduction in natural water is controlled by its $\mathrm{Hg} / \mathrm{DOC}$ ratio. Geochim Cosmochim Acta, 2009, 73: 6704-6715

39 Estrade N, Carignan J, Sonke J E, et al. Mercury isotope fractionation during liquid-vapor evaporation experiments. Geochim Cosmochim Acta, 2009, 73: 2693-2711

40 Zheng W, Foucher D, Hintelmann H. Mercury isotope fractionation during volatilization of $\mathrm{Hg}(0)$ from solution into the gas phase. J Anal Atom Spectrom, 2007, 22: 1097-1104

41 Lindberg S, Bullock R, Ebinghaus R, et al. A synthesis of progress and uncertainties in attributing the sources of mercury in deposition. Ambio, 2007, 36: 19-32

Open Access This article is distributed under the terms of the Creative Commons Attribution License which permits any use, distribution, and reproduction in any medium, provided the original author(s) and source are credited. 